\title{
АЛЬФА И ОМЕГА: ИДИОМЫ С ОДИНАКОВОЙ ВНУТРЕННЕЙ ФОРМОЙ В РУССКОМ, АНГЛИЙСКОМ И НЕМЕЦКОМ ЯЗЫКАХ
}

\author{
АНАСтАСИЯ КОЗЕРЕНКО \\ Институт русского языка им. В.В. Виноградова РАН
}

Исследования семантики идиом показывают, что внутренняя форма в большинстве случаев влияет на актуальное значение и употребление идиомы (ср. Баранов \& Добровольский (2008) и, ранее, Баранов \& Добровольский (1998), а также работы Арутюнова (1997) и Зализняк (1998) о месте внутренней формы в описании лексики). В случае если внутренняя форма идиомы достаточно прозрачна и осознается носителями языка, ее следует учитывать в толковании (ср. реализацию этого подхода во фразеологическом словаре (Баранов А.Н., Добровольский Д.О. 2009)).

Известно, что существует ряд идиом, переводные эквиваленты которых в других языках имеют схожую лексическую структуру и ту же или очень близкую внутреннюю форму. Возникает естественный вопрос: совпадает ли в разных языках значение и употребление этих идиом?

Так, в книге Dobrovol'skij \& Piirainen (2005) приводится в качестве примера идиома сuдеть в четырех стенах. Идиомы с идентичной лексической структурой имеются во многих языках. Выясняется, что соответствующие идиомы в немецком, греческом и финском языках имеют значение 'находиться у себя дома в атмосфере уединения и защищенности' и имеют положительные коннотации. В немецком, французском и русском языках такие идиомы имеют значение 'постоянно находиться дома, не выходя из него, в атмосфере изоляции, скуки, запертости' и имеют отрицательные коннотации. Кроме того, в датском и французском языках соответствующие идиомы имеют значение 'сидеть в тюрьме'. Таким образом, мы видим, что одна и та же лексическая структура идиомы может активировать в сознании носителя языка различные фреймы - дома со стенами, которые могут защищать или ограничивать перемещение, или тюремной камеры (см. (Dobrovol'skij \& Piirainen 2005, 117118)).

В работе Козеренко (2003) мы рассматривали ряд идиом, описывающих эмоции радость и горе в трех языках: на седьмом небе [om счастья] [быть ... ]; седьмое небо $\sim$ [to be ... ] in seventh heaven $\sim$ im siebten/siebenten Himmel [sein/sich fühlen ... ]; бальзам на (чьё-л.) сердце/ (чьи-л.) раны/(чью-л.) душу 
[to be] as balm to one's wounds $\sim$ wie Balsam auf j-s Wunden [sein ... ]; pвать [на себе] волосы $\sim$ to tear one's hair out $\sim$ sich die Haare raufen; сердие кровью обливается (у кого-л.); душа кровью обливается $\sim$ one's heart bleeds $\sim j$-m blutet das Негz; лить слёзы/слёзки (по кому-л./чему-л.); проливать слёзы (по кому-л./чему$\pi$.) $\sim$ to weep bitter tears $\sim$ Tränen vergießen. Было продемонстрировано, что в одних случаях компоненты значения и особенности употребления русской идиомы, обусловленные ее внутренней формой, обнаруживаются и в контекстах употребления соответствующей английской или немецкой идиомы, а в других - английский или немецкий близкий аналог русской идиомы обнаруживает элементы значения, которых нет у соответствующей русской идиомы или употребляется в контекстах, отличных по своим свойствам от контекстов употребления русской идиомы.

Для того, чтобы ответить на вопрос об эквивалентности таких идиом, мы рассматриваем идиомы с аналогичной или схожей внутренней формой в русском, английском и немецком языках и на основе множественных контекстов из современной литературы, публицистики и речевого общения в сети Интернет фиксируем сходства и различия в их значении и употреблении. Наша гипотеза заключается в том, что внутренняя форма, позволяя объяснить наличие некоторых компонентов значения идиомы или ряд особенностей ее употребления, тем не менее, не предсказывает всех особенностей ее значения и поведения в контексте. Идиомы, имеющие близкую или одинаковую внутреннюю форму в разных языках, практически никогда не являются полными эквивалентами друг друга. При детальном изучении их употребления в соответствующих языках неизменно в одном языке обнаруживаются особенности значения или употребления, не свойственные аналогичной идиоме в другом языке.

В настоящей работе мы хотим продолжить сопоставительное описание идиом с одинаковой внутренней формой в русском, английском и немецком языках и рассмотреть идиому альфа и омега и ее английский и немецкий эквиваленты the Alpha and Omega, Alpha und Oтеga. Идиома альфа и омега изначально восходит к новозаветному библейскому тексту:

(1) Я есмь Альфа и Омега, начало и конец, говорит Господь, Который есть, и был, и грядет, Вседержитель.

Откровение святого Иоанна Богослова, 1.8

Соответственно, во внутренней форме идиомы может содержаться отсылка к этому библейскому эпизоду в той или иной интерпретации. Кроме того, альфа и омега являются первой и последней буквами греческого алфавита, что также может реализоваться во внутренней форме. Традиционно русские словари выделяют у этой идиомы 2 значения (ср. словари Лубенская 1997, ФСРЯ 
2002, Яранцев 2001, Мокиенко 1997¹):

1. Начало и конец чего-л.

2. Сущность, основа, самое главное

При этом на первое значение примеры либо не приводятся (ср. Лубенская 1997), либо эти примеры устаревшие ${ }^{2}$, либо они не соответствуют данному значению. Ср. следующие примеры из словаря Яранцев 2001:

(2) У нее в мире никого нет, кроме него, он один для нее все - закон, родство, природа, начало и конец, альфа и омега ее бытия, все, все.

И.И. Лажечников. Ледяной дом

(3) Первым и последним словом, альфой и омегой всей его жизни было, как у всех поэтов, - его собственное я.

И.С. Тургенев. Рецензия на «Фауст» Гете

(4) Для многих ученых диссертация стала альфой и омегой их научной карьеры, средоточием их помыслов на много лет вперед, иногда на всю активную жизнь.

И. Бестужев-Лада, Середняк в науке

(5) - Вам когда-нибудь доводилось быть пайщиком жилкооп-товарищества? Нет? Значит, вы не знаете жизни. Современный жилищный кооператив это, если хотите знать, альфа и омега, начало всех начал в текущем быту интеллигента средней руки.

В. Максимов. Карантин

Из приведенных примеров только (4) может быть проинтерпретирован как употребление идиомы в первом значении, ср.: Для многих ученых диссертация стала началом и кониом их научной карьеры. Впрочем, этот же пример может быть проинтерпретирован и как употребление идиомы во втором значении, ср.: Для многих ученых диссертация стала самым главным в их научной карьере, средоточием их помыслов на много лет вперед, иногда на всю активную жизнь.

Среди многочисленных рассмотренных нами примеров употребления этой идиомы ${ }^{3}$ был обнаружен только один, претендующий на интерпретацию в первом значении:

(6) Он уже быстро срывал бумажные листы один за другим со свёртка и наконец бросил на стол чёрный, обугленный предмет - не то камень,

[1] В словаре Мокиенко отмечено одно значение, однако оно включает описание обоих значений.

[2] Современными примерами мы считаем примеры из литературы, публицистики или речевого общения не ранее 60-х годов 20-го века.

[3] Поиск примеров производился в Национальном корпусе русского языка, Базе данных по русской фразеологии (см. список используемых корпусов текста в конце статьи), а также в русскоязычном сегменте Интернета. 
не то хлебную корку, неправильно-сферической формы. Затем снял газету с «красной леди» и положил на неё и эту обуглившуюся, покоробленную временем кость. Так они лежали вместе - большой розовый череп и чёрный круглый костяной обломок. - Ну вот и гейдельбержец тут, — сказал он ублаготворенно, — вся компания, значит, альфа $u$ омега. Низшие и высшие. Все тут, у меня на столе. Теперь пусть разбираются, кто от кого.

Ю.О. Домбровский. Обезьяна приходит за своим черепом

Однако, по нашему мнению, в данном случае имеет место нестандартное употребление: был реализован потенциал членимости идиомы - аль $ф a$ $u$ омега в данном случае указывают на 2 разных субъекта, в то время как при стандартном употреблении альфа и омега согласуется с одним субъектом (ср. примеры (2)-(6)).

Как следствие из вышесказанного, далее мы будем считать, что идиома альфа и омега не используется в современном русском языке в значении 'начало и конец'4

Остановимся подробнее на значении идиомы 'сущность, основа, самое главное'. В этом значении идиома широко употребляется в современном русском языке. Вот как она протолкована в словаре (Баранов А.Н., Добровольский Д.О. 2009):

АЛЬФА и ОМЕГА (чего-л.) книжн. самая существенная часть чего-Л., без которой его не было бы как такового, подобно тому, как не существовал бы алфавит без его первой и последней букв основа, суть, сущность.

В толковании элементы значения, унаследованные от внутренней формы идиомы, выделены курсивом; затем приведены однословные квазисинонимы идиомы ${ }^{5}$. Ср. типичные примеры употребления этой идиомы:

(7) Российское - советское - русское государство всегда двигалось вперед за счет ограбления своего собственного народа. Это - суть, квинтэссенция, альфа и омега даже и реформаторской деятельности в России, не говоря уже о нереформаторской.

Независимая газета, 1996

(8) Альфа и омега марксизма - постоянная борьба, та самая перманентная революция, которой всегда следовали большевики с тех пор, как они вышли на баррикады первой русской революции.

А. Яковлев. Омут памяти

[4] Англоязычные словари также выделяют такое значение (cp. The Oxford English Dictionary: alpha and omega refers to any beginning and ending; TheFreeDictionary: both the beginning and the end),что также не подтверждается контекстами.

[5] Подробнее о формате толкования см. Добровольский (1996), О пользовании словарем. 
В дальнейшем мы будем говорить об этом значении как о единственном в русском языке. $^{6}$

Субъектная валентность идиомы и дополнение в родительном падеже заполняются элементами непредметной лексики (как правило, абстрактными понятиями), ср. необычность в русском языке таких выражений, как * фрукты - альфа и омега любой диеть; “ стулья - альфа и омега мебельной промышленности. В прототипическом случае речь идет о некоторой понятийной области, выраженной дополнением, в которой выделяется меньшая понятийная область, 'самое важное', которая описывается субъектом.

В качестве исключения можно указать на игровой иронический контекст употребления идиомы, где эффект комичности достигается в том числе за счет нарушения правил заполнения субъектной валентности:

(9) Граждане! Уважайте пружинный матрац в голубых цветочках! Это семейный очаг, альфа и омега меблировки, общее и целое домашнего уюта, любовная база, отец примуса! Как сладко спать под демократический звон его пружин! Какие сладкие сны видит человек, засыпающий на его голубой дерюге! Каким уважением пользуется каждый матрацевладелец!

И. Ильф, Е. Петров. Двенадцать стульев

В отличие от русского, в английском и немецком языках возможно заполнение субъектной валентности идиомы как непредметной, так и предметной лексикой. Ср. примеры употребления идиомы the Alpha and Omega в английском и das Alpha und Omega (с вариантом das A und O) в немецком языках на первый и второй случаи:

(10) The wholeness and the oneness of life are the alpha and omega of medicine. Wall Street Journal, 2009

(11) Are mitochondria the alpha and omega of retinal disease? www.nick-lane.net/mitochondria

(12) Der Schutz des Geschäftsgeheimnisses ist das A und O für das wirtschaftliche Überleben.

www.skartacia.sk/de

(13) Gute Stoffe für die Dämmung sind das Alpha und Omega für effektiven Schutz vor Wärmeverlust, vor Schallschutz und Brandschutz. www.fertighaus-bauen.info

[6] В богословских текстах и на иконах $\alpha$ и $\omega$, Альфа и Омега, используются как одно из имен Бога (ср. Спаситель, Отец, Вседержитель и т.п.). В английском языке также выделяется такое значение, ср. The Oxford English Dictionary: Today people still sometimes use the capitalized form, Alpha and Omega, to denote the Divine Being. Это значение могло бы быть представлено с пометой сnеu., которая на настоящий момент не предусмотрена в нашем словаре, либо в рамках отдельного комментария в соответствующей словарной статье. 
Впрочем, следует отметить, что хотя англоязычные словари и приводят соответствующие примеры употребления, заполнение субъектной валентности конкретной лексикой все же встречается достаточно редко ${ }^{7}$, ср. информацию в словарях:

(14) Fruit is the alpha and omega of her diet. The Oxford English Dictionary

(15) Money is the alpha and omega of his existence. Webster Learner's Dictionary

Примеров, подобных (14) и (15), в реальных текстах обнаруживается крайне мало.

Отдельно следует остановиться на возможности заполнения субъектной валентности обозначением человека. Языковой материал показывает, что для русского языка такое употребление нетипично. Есть единичные контексты такого употребления в литературе 19-го века, ср. пример (2), а также в околоцерковных контекстах, ср.:

(16) Тот, кто приходит к отцу Александру, кто сейчас с ним, для него альфа и омега, все на свете. У батюшки происходит некий акт глубокой самоотдачи. С каждым приходящим возникают особые, непохожие на другие отношения. Человек чувствует себя любимым, интересным, важным, более того - единственным.

3. Масленикова. Жизнь отца Александра Меня

В силу тематической принадлежности контекстов подобных (16) мы считаем такое употребление псевдоцитатой библейского текста, отсылающей читателя к соответствующему семантическому полю понятий. В английском языке наблюдается схожая картина. Хотя отдельные словари указывают на возможность употреблений, подобных (2), (ср. пример (17)), в целом, судя по контекстам, такое употребление для английского языка также нетипично:

(17) He loved her deeply. She was his alpha and omega. TheFreeDictionary

В текстах обнаружен только один контекст такого вида:

(18) Finally, special presentations were given by Franz Grenet, regarding the Sogdian community in the silk road regions, and by Prods Oktor Skjærvø. The latter was the self-described "Alpha and Omega" of the symposium, who with characteristic vigor and energy gave both the opening and concluding lectures, presenting fascinating glimpses of the literature and folklore of Khotan.

www.silk-road.com/newsletter

[7] Здесь и далее мы опираемся на данные перечисленных в конце работы корпусов текстов, а также англо- и немецкоязычного сегментов Интернета. 
Однако в данном случае также имеет место псевдоцитата и языковая игра, cp. self-described "Alpha and Omega" - субъект осознанно уподобляет себя Богу, как центральной фигуре (в данном случае в рамках симпозиума), определяющей существование и функционирование всего окружающего мира.

В немецком языке употребление этой идиомы с обозначением человека в роли субъекта также крайне редко, обнаруживаются только единичные контексты такого вида:

(19) Seit wenigen Tagen weiß ich - nach unendlichen Tagen und Wochen der Ungewissheit - daß meine Mama sehr bald sterben wird. [...] ich erfuhr, daß meine Mutter durch und durch voller Metastasen ist. Ich weiß überhaupt nicht wie ich reagieren soll. Sie ist Alpha und Omega für mich . . . www.med1.de/Forum/Trauer

В английском языке встречаются также употребления идиомы the alpha and omega в несколько ином, хотя и близком значении, ср. следующие примеры:

(20) There's not really a lot that can be said here that hasn't already been said. Elvis, the alpha and omega of Rock'n'Roll. At number one at the very start and at number one even today!

www.cherryred.co.uk/revola/artists/elvispresley.php

(21) The Ward Brothers were the Alpha and Omega of 20th century decoy carving. The wood decoy block models they developed are truly representative of real American folk art.

Wikipedia

(22) [...] Hank is respected and adored by his peers for being a paragon of refinement, for inspiring by example, for remaining a guiding light as jazz has changed and evolved. «He's still the alpha and omega of the piano,» stated Williams at one point.

www.jazzreview.com

Субъектная валентность здесь также заполнена обозначением человека, однако значение идиомы меняется. Ср. невозможность замены: *Elvis, the most important part of Rock'n'Roll, *The Ward Brothers were the most important part of 20th century decoy carving, *He's still the most important part of the piano ${ }^{8}$.

В данном случае наблюдается контекстно-ориентированный семантический сдвиг (см. об этом в книге Падучева (2004)): в прототипическом случае

[8] Поскольку толкования предусмотрены только на руском языке (в рамках Фразеологического объяснительного словаря русского языка), при подстановке квазисинонимичного выражения в англоязычный контекст употребления соответствующей английской идиомы используется переводной эквивалент аналогичного русского квазисинонимичного выражения. 
субъект - некоторая понятийная область, выраженная непредметной лексикой, или, что допустимо, хотя и редко встречается в английском языке, предметной лексикой (ср. пример (11)) - является 'самым важным' в какой-то более широкой предметной области, обозначенной дополнением с предлогом of. Однако человек не может быть 'самым важным’ в какой-либо понятийной области. Следовательно при подставлении на место субъекта обозначения человека мы либо наблюдаем нестандартное употребление того или иного вида (ср. примеры (2), (6), (16), (18)), либо значение идиомы модифицируется. В примерах (20), (21), (22) значение идиомы можно описать как 'лучший в каком-л. виде деятельности', ср. возможность регулярной подстановки: Elvis, the best in Rock'n'Roll; The Ward Brothers were the the best in 20th century decoy carving; He's still the best in the piano. Таким образом, на основе сочетаемостных свойств идиомы в английском языке может быть выделено второе значение идиомы: 'самый лучший в каком-л. виде деятельности' (о человеке).

В немецком языке таких контекстов не было обнаружено, однако встречаются контексты следующего вида с конкретным названием (именем собственным) в качестве субъекта:

(23) Nikon D700. Das Alpha und Omega digitaler Kleinbildphotographie? www.stillephotographie.at/NikonD700 (в заголовке; Nikon D700 - название модели фотоаппарата)

(24) Kostenlose Online Spiele: Es gibt keine Gnade! River Raid ist Alpha und Omega der Schützen, das Spiel so berühmt, [. . .] www.forum.wiaderko.com/de/gry-inne-online (обсуждаются компьютерные игры; River Raid - название одной из них)

Ср. контекст такого же вида в английском:

(25) The Alpha and Omega of Motorcycles.

YouTube.com (заголовок видеоролика, демонстрирующего крутой мотоцикл)

По всей видимости, в данном случае реализуется второе значение идиомы ('самый лучший в какой-л. области'), хотя речь идет не о человеке, а о конкретном объекте. Существенно, что эти три примера встретились в наиболее динамично развивающихся областях языка - рекламных текстах и речевом общении Интернета. Судя по всему, здесь имеет место девальвация значения оценочного слова (в данном случае - идиомы), часто происходящая в рекламном и молодежном жаргонах. Ср. описание девальвации значений часто используемых в рекламе прилагательных элитный и эксклюзивный в книге Кронгауз (2007): элитный ранее подразумевало отбор, селекцию лучших образцов (ср. элитные сорта пшенищы), а эксклюзивный - предназначенность 
для одного единственного субъекта (ср. эксклюзивное интервью). В сегодняшних рекламных текстах эти слова фактически стали синонимическими прилагательными с абстрактно-положительной семантикой, ср. такие употребления, как элитные холодильники или эксклюзивная баранина (см. (Кронгауз 2007, 29-31)).

Таким образом, в современном языке рекламы и молодежном жаргоне английского и немецкого языков можно зафиксировать значение идиомы 'caмый лучший в какой-л. области’ (применительно к конкретной лексике).

Мы рассмотрели варианты заполнения субъектной валентности и дополнения, выраженного в русском языке родительным падежом, в английском предлогом of, в немецком - также родительным падежом. Кроме этих двух валентностей в немецких контекстах часто реализуется еще одна, ср. следующий пример (а также примеры (12), (13), (19)):

(26) So ist bei aller Psychohygiene die Erhaltung und Pflege der Gesundheit zunächst das Alpha und Omega für den alten Menschen.

J. Rattner, G. Danzer. Psychosomatik und Psychohygiene: Ein Gesundheitsbuch für Leib, Seele und Geist

Так же как при употреблении русской идиомы с непредметной лексикой, субъектная валентность здесь заполнена абстрактным понятием (die Erhaltung und Pflege der Gesundheit), которое объявляется 'самым важным'. При этом более общая область, в которой это понятие является самым важным (обычно выражаемая дополнением в родительном падеже), опущена, зато присутствует дополнение, вводимое предлогом für (für den alten Menschen), и обозначающее того, для кого актуальна заявленная важность ${ }^{9}$. В английском и русском языках такое управление идиомы также возможно, однако встречается достаточно редко; нормативность подобных употреблений в русском языке сомнительна, ср.:

(27) Energy savings are alfa and omega for solving the challenges of the future with regard to energy in the most cost-effective way. Danish Society of Engineers' Energy Plan 2030

(28) ? Корпоративный стиль в одежде - это альфа и омега для любой серьезной компании на российском рынке.

Итоги, 2006

(29) ?? Много движения - вот альфа и омега для здоровых детских ножек. Поэтому позволяйте детям как можно больше ходить босиком. www.moi-roditeli.ru

[9] Бенефициант в терминологии семантических падежей Ч. Филлмора. 
В английском языке идиома the Alpha and Omega встречается еще в одном значении, которое можно сформулировать как 'полное описание некоторой тематической области', и которое встречается исключительно в заголовках или названиях, ср. такие примеры, как:

(30) Alpha and omega of microbes. Antibiotics and probiotics: judicious use is the key. Canadian Family Phisician, 2004 (заголовок)

(31) The Alpha and Omega of Greek Cooking.

S. Krieg (название книги)

В русском языке такое употребление идиомы альфа и омега невозможно, cр. * Альфа и омега фотошопа, при норме Фотошоп от А до Я. В немецком примеров на употребление идиомы das Alfa und Omega в этом значении обнаружено также не было.

В данном значении регулярно выступают такие идиомы, как от $A$ до Я, om альфа до омеги, от аза до ижицы, from Alfa to Omega, from A to Z, von Alfa bis Omega, von $A$ bis $O$, von $A$ bis $Z$, однако детальное сопоставительное описание этого параллельного ряда идиом остается за рамками настоящей статьи из соображений места.

Итак, были рассмотрены идиомы альфа и омега и ее английский и немецкий эквиваленты the Alpha and Omega, Alpha und Omega. Были выявлены следующие семантико-синтаксические особенности этих идиом в соответствующих языках:

- в русском языке идиома альфа и омега употребляется только в одном значении: 'самая существенная часть чего-л., без которой его не было бы как такового’;

- субъектная валентность идиомы в русском языке заполняется единицами непредметной лексики (как правило, абстрактными понятиями), заполнение субъектной валентности конкретными понятиями или обозначениями человека нетипично для русского языка;

- в английском и немецком языках возможно заполнение субъектной валентности соответствующих идиом Alpha and Omega, Alpha und Omega конкретными понятиями;

- в английском и немецком языках возможно заполнение субъектной валентности обозначениями человека; в этом случае происходит сдвиг значения; при обозначении человека идиома употребляется в значении ‘лучший в каком-л. виде деятельности’; 
- в рекламных текстах и молодежном интернет-общении на английском и немецком языках встречается употребление данных идиом в значении 'самый лучший в какой-л. области' (применительно к конкретной лексике);

- в русском, английском и немецком языках у обсуждаемых идиом есть факультативная валентность, выраженная дополнением с предлогами для, for и für соответственно, обозначающим того, для кого актуальна важность; при этом в немецком языке заполнение этой валентности достаточно регулярно и часто сопровождается опущением дополнения в родительном падеже; в английском языке заполнение этой валентности редко встречается; для русского языка оно нетипично;

- идиома Alpha and Omega в английском языке также употребляется в значении 'полное описание некоторой тематической области'; это значение встречается исключительно в заголовках или названиях; в русском и немецком языках употребление соответствующих идиом в этом значении не зафиксировано.

Полученные данные свидетельствуют о том, что, как и предполагалось ранее, идиомы разных языков, имеющие идентичный лексический состав, a также близкую или идентичную внутреннюю форму, все же демонстрируют достаточное количество существенных различий в значении и употреблении.

ИСПОЛЬЗУЕМЫЕ СЛОВАРИ И КОРПУСА ТЕКСТОВ:

Любенская 1997 - Лубенская С. И. Русско-английский фразеологический словарь. М., 1997.

Мокиенко 1997 - Мелерович А. М., Мокиенко В. М. Фразеологизмы в русской речи. Словарь. М., 1997.

Яранцев 2001 - Яранцев Р. И. Русская фразеология. Словарь-справочник: Ок. 1500 фразеологизмов. М., 2001.

ФСРЯ 2002 - Фразеологический словарь русского языка // Составители: Л. А. Войкова, В. П. Жуков, А. И. Молотков, А. И. Фёдоров / Под ред. А. И. Молоткова, издание третье, стереотипное. М., 2002.

Телия 2006 - Большой фразеологический словарь русского языка. Значение. Употребление. Культурологический комментарий / Отв. Ред. В. Н. Телия. М., 2006. 
Баранов А. Н., Добровольский Д. О., 2009 - Баранов А. Н., Вознесенская М. М., Добровольский Д. О., Киселева К. Л., Козеренко А. Д. Фразеологический объяснительный словарь русского языка. М., 2009.

Lingvo - ABBYY Lingvo 12, Электронный словарь.

Кунин 2006 - Кунин А. В. Большой англо-русский фразеологический словарь. M., 2006.

Мальцева 2004 - Мальцева Д. Г. Немецко-русский словарь современных фразеологизмов. М., 2004.

Collins English Dictionary - Collins English Dictionary, 8th Edition, Cambridge, 2006

The Oxford English Dictionary - The Oxford English Dictionary, Second Edition, Oxford, 2005.

Webster Learner's Dictionary - Webster Learner's Dictionary, New York, 2001

TheFreeDictionary - www.thefreedictionary.com.

Национальный корпус русского языка База данных по русской фразеологии

(ИРЯ им. В. В. Виноградова РАН, Отдел экспериментальной лексикографии).

British National Corpus (BNC).

Collins Birmingham University International Language Database (COBUILD).

British Academic Spoken English Corpus (BASE).

The British Academic Written English (BAWE).

Textkorpora des Institutes für Deutsche Sprache (IDS), Mannheim.

Das Digitale Wörterbuch der deutschen Sprache des 20. Jh. (DWDS).

СПИСОК ЛИТЕРАТУРЫ

Арутюнова, Н. Д. 1997. О стыде и стуже. Вопросы языкознания 2.

Баранов, А. Н. и Д. О. Добровольский. 1998. Внутренняя форма идиом и проблема толкования. Известия АН. Серия литературы и языка 57(1). 
Баранов, А. Н. и Д. О. Добровольский. 2008. Аспекть теории фразеологии. М.

Добровольский, Д. О. 1996. Образная составляющая в семантике идиом. Вопросы языкознания 1.

Зализняк, А. А. 1998. О месте внутренней формы слова в семантическом моделировании. В кн. Труды Международного семинара Диалог'98 по компьютерной лингвистике и ее приложениям, Казань.

Козеренко, А. Д. 2003. Внутренняя форма идиом в сопоставительном аспекте. В кн. Трудь Международного семинара Диалог'2003 по компьютерной лингвистике и ее приложениям, Протвино.

Кронгауз, М. А. 2007. Русский язык на грани нервного срыва. М.

Падучева, Е. В. 2004. Динамические модели в семантике лексики. М.

Dobrovol'skij, D. \& E. Piirainen. 2005. Figurative Language: Cross-cultural and Crosslinguistic Perspectives. Emerald Group Pub Ltd.

АДРЕС АВТОРА

Анастасия Козеренко

Институт русского языка им. В.В. Виноградова РАН

Москва

Россия

akozerenko@gmail.com 